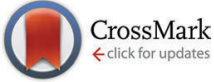

Cite this: Chem. Commun., 2015, 51,6932

Received 24th January 2015, Accepted 12th March 2015

DOI: $10.1039 / \mathrm{c5cc00693g}$

www.rsc.org/chemcomm

\section{Tetrabenzocircumpyrene: a nanographene fragment with an embedded peripentacene core $\dagger$}

\author{
Ruth Dorel, ${ }^{a}$ Carlos Manzano, ${ }^{b}$ Maricarmen Grisolia, ${ }^{c}$ We-Hyo Soe, ${ }^{b}$ \\ Christian Joachim ${ }^{c}$ and Antonio M. Echavarren ${ }^{\star a d}$
}

\begin{abstract}
A new disc-shaped highly symmetric $\mathrm{C}_{54} \mathrm{H}_{20}$ nanographene fragment, tetrabenzocircumpyrene, has been synthesized and characterized by scanning tunnelling microscopy, demonstrating the potential of this technique for identifying highly insoluble graphenic molecules.
\end{abstract}

Large polycyclic aromatic hydrocarbons (PAHs) have recently attracted much attention due to their unique electronic and self-assembly properties, which provide a wide range of opportunities for the fabrication of novel devices. ${ }^{1}$ One of the challenges in this area is the development of efficient synthetic methodologies for the preparation of well-defined sections of graphene (nanographenes). In this regard, novel organic protocols have been developed, although they are always limited by the low solubility of planar aromatic molecules and the number of side reactions that may take place, which increase with the molecular weight. ${ }^{2}$ Disc-shaped molecules are of particular interest since they are able to self-organize into columnar phases and therefore can be used as conducting layers in organic molecular electronics. ${ }^{3}$ One of the most extensively studied discotic PAH is hexa-peribenzocoronene (HBC), also known as 'superbenzene', owing to its intrinsic charge-carrier ability. ${ }^{4}$ It is predictable that enlarging the aromatic framework would enhance the columnar order due to more intense $\pi-\pi$ interactions and, consequently, charge mobility. The stacking of PAHs as prototypes for graphene multilayers has been theoretically studied, finding that the binding energies strongly depend on the size of the PAHs. ${ }^{5}$ On the other hand, there is growing interest in acene-based molecules such as

\footnotetext{
${ }^{a}$ Institute of Chemical Research of Catalonia (ICIQ), Av. Països Catalans 16, 43007 Tarragona, Spain. E-mail: aechavarren@iciq.es

${ }^{b}$ IMRE, $A^{*}$ STAR (Agency for Science, Technology and Research), 3 Research Link, 117602, Singapore

${ }^{c}$ GNS \& MANA Satellite, CEMES-CNRS, 29 rue J. Marvig, 31055 Toulouse Cedex, France

${ }^{a}$ Departament de Quimica Analítica i Química Orgànica, Universitat Rovira $i$ Virgili, C/Marcel li Domingo s/n, 43007 Tarragona, Spain

$\dagger$ Electronic supplementary information (ESI) available. CCDC 1035605-1035610. For ESI and crystallographic data in CIF or other electronic format see DOI: $10.1039 / \mathrm{c} 5 \mathrm{cc} 00693 \mathrm{~g}$
}

periacenes, which are conjugated systems with two rows of peri-fused acenes. ${ }^{6}$ These compounds might serve as biradical materials, and are believed to be suitable materials for spintronic, electronic, optical, and magnetic devices. Small periacenes have been known for a long time, and recently larger analogues such as teranthene and quarteranthene have been described. ${ }^{7}$ However, the synthesis of large periacenes such as peritetracene or peripentacene has not been achieved yet, ${ }^{8}$ although peripentacene has been detected by sublimation of pentacene by mass spectrometry. ${ }^{9}$

Motivated by its promising properties, we targeted tetrabenzocircumpyrene 1a, a yet unreported highly symmetric disc-shaped nanographene fragment containing 54 carbon atoms. Polyarene 1a includes a peripentacene core and can be considered as a 'expanded HBC' (Fig. 1). According to that expected, ${ }^{10,11}$ DFT calculations predicted a $c a .30 \%$ decrease in the HOMO-LUMO gap in going from HBC $(3.59 \mathrm{eV})$ to tetrabenzocircumpyrene $1 \mathrm{a}(2.45 \mathrm{eV})$.

Our retrosynthetic approach for the synthesis of 1a considers the formation of the final nanographene fragment by means of

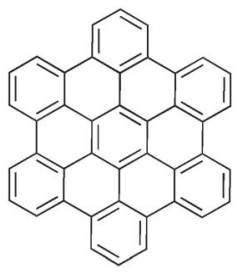

Hexabenzocoronene (HBC)

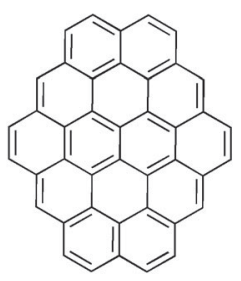

Circumpyrene

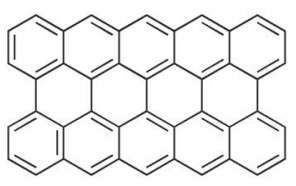

Peripentacene

Tetrabenzocircumpyrene (1a)

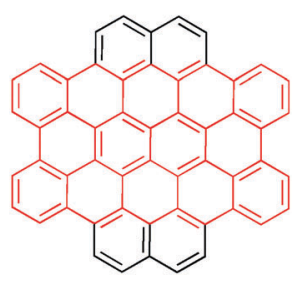

Fig. 1 Structures of HBC, peripentacene, circumpyrene and tetrabenzocircumpyrene $1 \mathbf{1 a}$. 

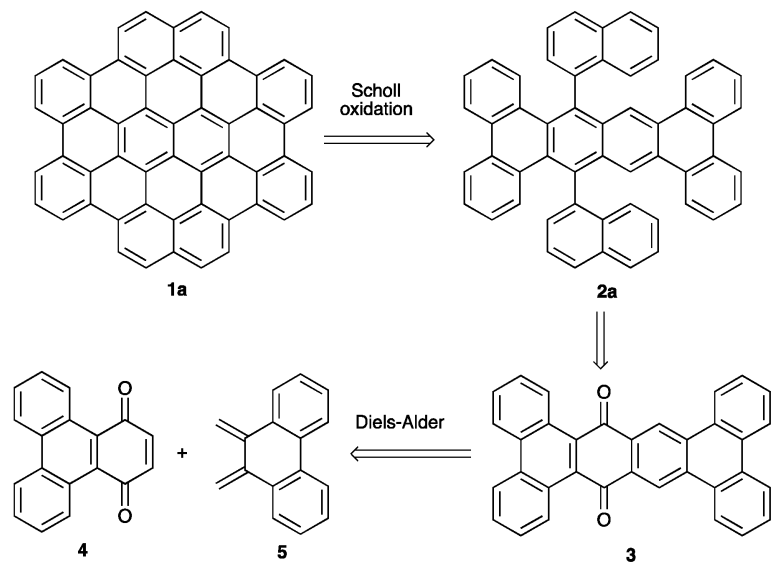

Scheme 1 Retrosynthetic analysis of tetrabenzocircumpyrene (1a).

Scholl oxidation from 9,20-di(naphthalen-1-yl)tetrabenzo[a,c,j,l]tetracene (2a) in which six $\mathrm{C}-\mathrm{C}$ bonds would be formed in a single step (Scheme 1). Polyarene $2 \mathrm{a}$ could be obtained by double nucleophilic addition of the naphthyl moieties to quinone 3, which could result from Diels-Alder cycloaddition between quinone 4 and $o$-quinodimethane 5. Quinone 4, the starting point of our synthesis, has been prepared by oxidation of triphenylene with excess $\mathrm{H}_{2} \mathrm{O}_{2}$, albeit in low yield. ${ }^{12}$ However, when we tried to scale up this reaction, the yield dropped significantly to 1-6\%. After some optimization, we found that by using $\mathrm{CrO}_{3}$ as the oxidant in the presence of 18-crown- $6,{ }^{13}$ multigram amounts of quinone 4 could routinely be obtained in up to $41 \%$ yield.

We chose 6 as a precursor of diene 5, which was generated in situ $^{14}$ and subjected to Diels-Alder cycloaddition with 4 to form a non-isolable adduct which spontaneously underwent oxidation to give a mixture of quinones 3 and $3^{\prime}$ in $70 \%$ yield (Scheme 2). Treatment of this mixture with DDQ did not result in the complete oxidation of $\mathbf{3}^{\prime}$ to 3 , presumably due to the low solubility of these compounds in standard organic solvents. For this reason we decided to continue the synthesis using a mixture of both quinones. Double nucleophilic addition of 1-naphthyllithium to $3 / \mathbf{3}^{\prime}$ afforded the crude mixture of diols 7syn, 7anti, $7^{\prime}$ syn and $7^{\prime}$ anti, which was directly reduced by treatment with $\mathrm{HI}$ in acetic acid. Without isolation, this mixture was treated with DDQ in toluene to give key intermediate 2a as a $5: 1$ mixture of anti : syn rotational isomers (Fig. 2). ${ }^{15}$ Final Scholl cyclodehydrogenation of $2 \mathbf{a}$ in the presence of excess of $\mathrm{FeCl}_{3}$ gave the target nanographene fragment 1a in $96 \%$ yield. The synthesis of tetrabenzocircumpyrene (1a) proceeds in just six steps, requires only two chromatographic purifications, and every step can be conducted on a gram scale (1.02 $\mathrm{g}$ of $1 \mathrm{a}$ were prepared in a single round from $6 \mathrm{~g}$ of triphenylene).

The extreme insolubility of this compound precluded its characterization by NMR spectroscopy. However, we were able to obtain a clean MALDI+ mass spectrum in which we could only identify one peak corresponding to the mass and isotopic pattern of 1a. Furthermore, we attempted the characterization of 1a by means of scanning tunnelling microscopy (STM). STM

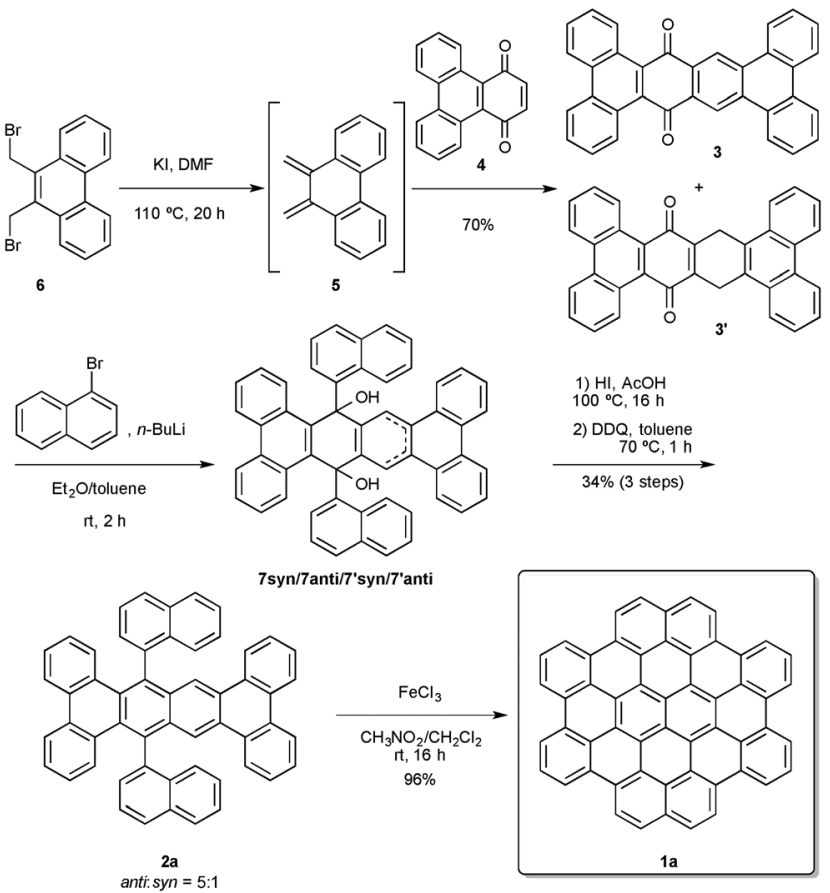

Scheme 2 Synthesis of $1 \mathbf{a}$.

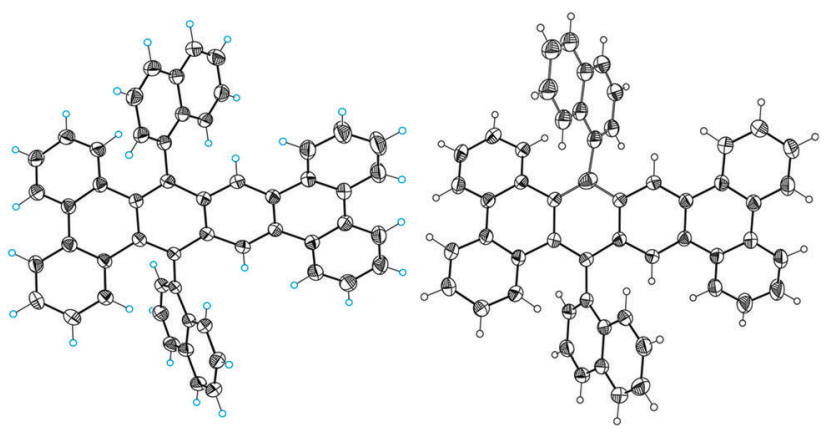

Fig. 2 ORTEP plot (50\% thermal ellipsoids) of the crystal structure of $\mathbf{2 a}$-anti (left) and 2a-syn (right).

and differential conductance $(\mathrm{d} I / \mathrm{d} V)$ imaging in conjunction with tunnelling spectroscopy were used respectively to obtain topographic images of 1a molecules deposited on an $\mathrm{Au}(111)$ surface and to characterize their molecular electronic states. $\mathrm{d} I / \mathrm{d} V$ mapping of single $\mathbf{1 a}$ molecules at resonances captured in the spectra allowed us to imagine the spatial distribution of molecular electronic states. Electron Scattering Quantum Chemical (ESQC) calculations including all the elements of the experimental method, i.e. the substrate, 1a molecule and STM tip, were done in order to assign the experimental $\mathrm{d} I / \mathrm{d} V$ images to the corresponding molecular orbitals.

The topographic, $\mathrm{d} I / \mathrm{d} V$ and computed images are shown in Fig. 3. The experimental $\mathrm{d} I / \mathrm{d} V$ images were taken at voltages corresponding to two resonances captured in the $\mathrm{d} I / \mathrm{d} V$ spectra of a single 1a molecule, namely at $-0.75 \mathrm{eV}$ and $1.65 \mathrm{eV}$ (see ESI $\dagger$ ). The maps computed at the energies corresponding to HOMO and LUMO orbitals showed identical features to those from the experimental 


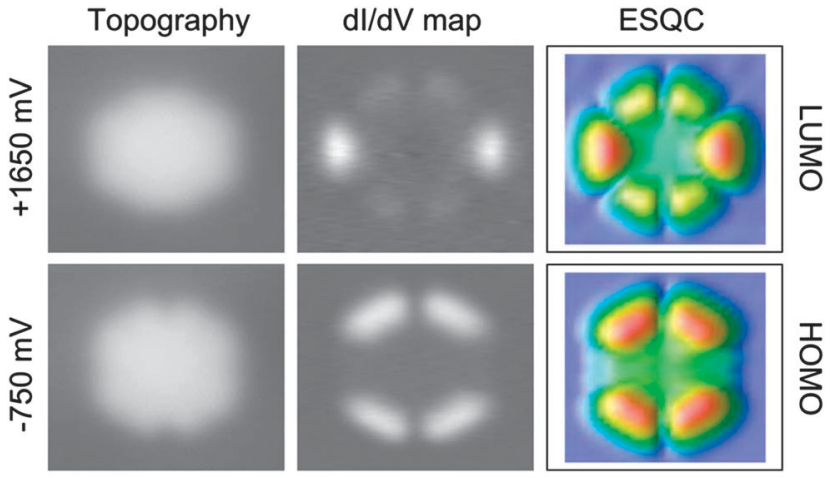

Fig. 3 (left) Topographic STM images of tetrabenzocircumpyrene (1a) taken at $-0.75 \mathrm{~V}$ and $1.65 \mathrm{~V}$, the bias voltages corresponding to the resonances at positive and negative voltage nearest to the substrate's Fermi level. (center) $\mathrm{d} / / \mathrm{d} V$ maps taken concurrently at the same voltages showing the spatial distribution of the molecule's electronic density (images size: $3.2 \times 2.8 \mathrm{~nm}$ ). (right) ESQC computed images calculated at energies corresponding to HOMO and LUMO of $1 \mathrm{a}$

$\mathrm{d} I / \mathrm{d} V$ images, clearly confirming the structure assigned to tetrabenzocircumpyrene 1a. The experimental $2.40 \mathrm{eV}$ HOMO-LUMO gap determined on 1a deposited on $\mathrm{Au}(111)$ is fully consistent with the calculated value of $2.45 \mathrm{eV}$ in the gas phase (DFT, B3LYP/6-31G(d)).

We also considered the extension of this synthetic route to prepare tetrabenzocircumpyrene derivatives by using substituted 1-bromonaphthalenes as the starting materials for the double nucleophilic addition to the mixture of $\mathbf{3}$ and $\mathbf{3}^{\prime}$ (Scheme 3). Thus, we prepared dialkyltetrabenzocircumpyrenes $\mathbf{1 b}$ and $\mathbf{1 c}$, as well as the higher analogue hexabenzocircumpyrene 1d. The structure of the direct precursors of nanographene fragments 2b-d could be confirmed by X-ray diffraction (Fig. 4). ${ }^{15}$

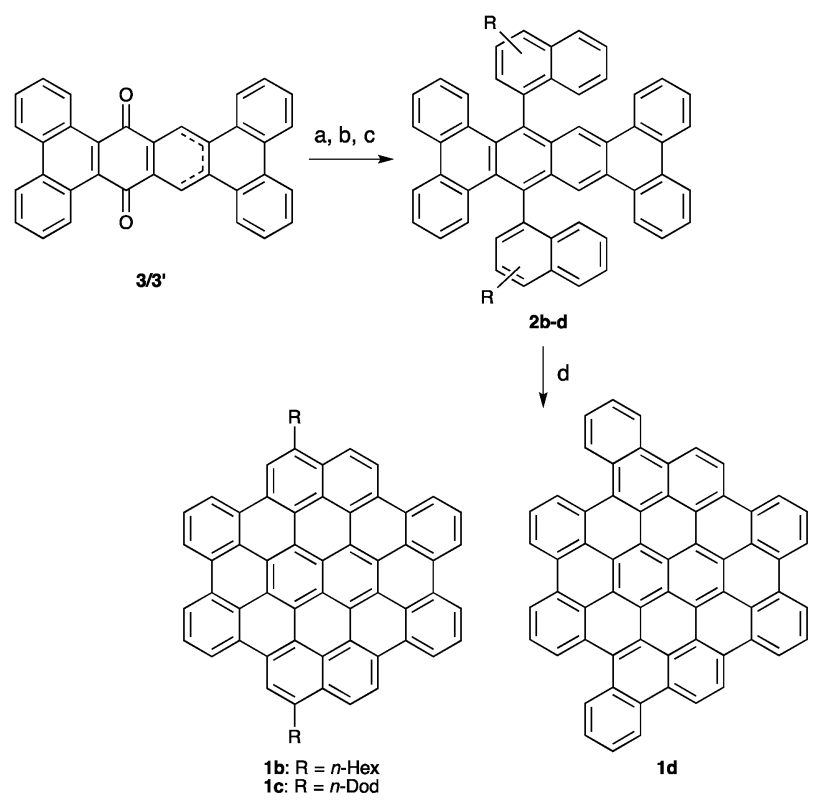

Scheme 3 Synthesis of tetrabenzocircumpyrene derivatives. (a) $\mathrm{ArBr}$, n-BuLi, Et ${ }_{2} \mathrm{O} /$ toluene, rt, 2 h (2b, 32\%; 2c, 26\%; 2d, 38\%); (b) $\mathrm{HI}, \mathrm{AcOH}$, $100{ }^{\circ} \mathrm{C}, 16 \mathrm{~h}$; (c) $\mathrm{DDQ}$, toluene, $70{ }^{\circ} \mathrm{C}, 1 \mathrm{~h}$; and (d) $\mathrm{FeCl}_{3}, \mathrm{CH}_{3} \mathrm{NO}_{2} / \mathrm{CH}_{2} \mathrm{Cl}_{2}$, rt, 16 h (1b, 85\%; 1c, 54\%; 1d, 64\%).
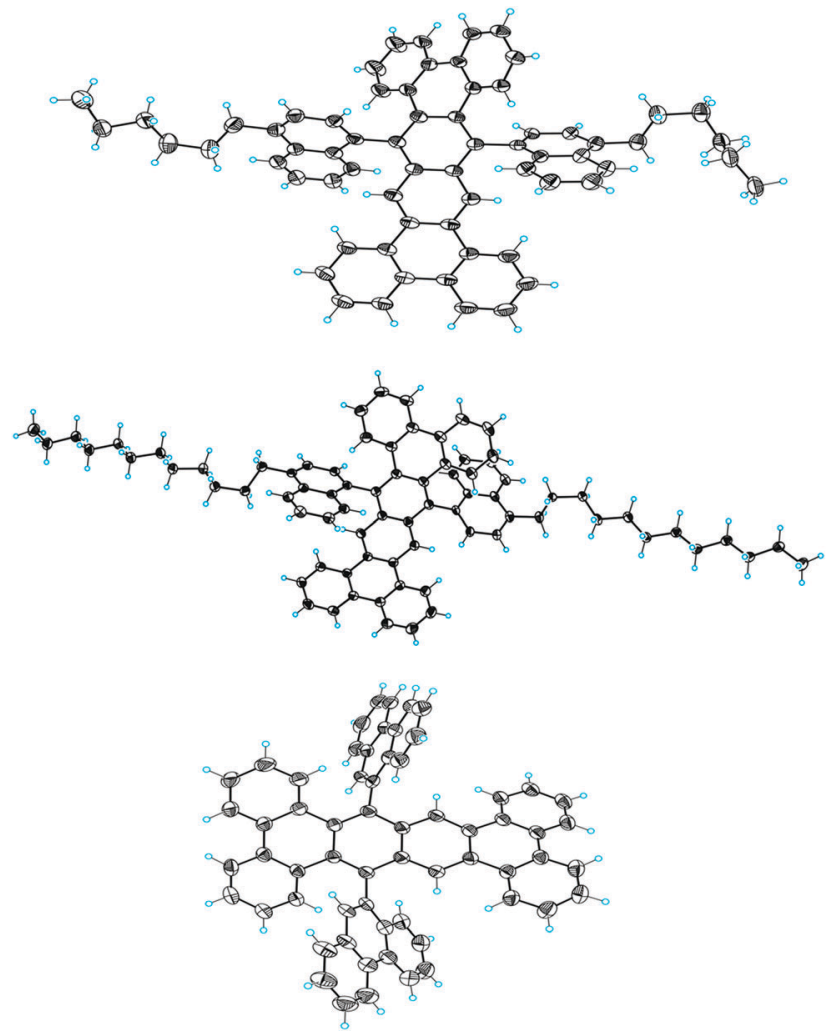

Fig. 4 ORTEP plot (50\% thermal ellipsoids) of the crystal structures of $\mathbf{2 b}$ (top), 2c (center) and $\mathbf{2 d}$ (bottom).

We observed that when we treated alkyl-substituted precursors of nanographene fragments with $\mathrm{FeCl}_{3}$ two products were formed. We decided to use $\mathbf{2 b}$ as a model substrate to examine this transformation in detail (Scheme 4). The major product was the expected dialkyltetrabenzocircumpyrene $\mathbf{1 b}$, which could be easily separated by filtration. After meticulous purification, we were able to isolate from the filtrate a brown solid slightly more soluble in organic solvents at temperatures over $100{ }^{\circ} \mathrm{C}$. This solid could be crystallized and the structure was confirmed to be $\mathbf{8}$ by X-ray diffraction (Fig. 5). ${ }^{15}$ This partially fused polyarene shows a contorted aromatic surface, which might also be of interest in material science. ${ }^{16}$ To prove if partially cyclized $\mathbf{8}$ was an intermediate in the formation of $\mathbf{1 b}$, we resubjected $\mathbf{8}$ to the oxidative cyclization conditions. However, after $24 \mathrm{~h}$ only unchanged 8 could be detected by mass spectrometry, demonstrating that this polyarene is not an intermediate in the formation of $\mathbf{1 b}$, but rather a product resulting from a competitive pathway. This result further demonstrates that not all the conceivable pathways in Scholl cyclodehydrogenation processes are equally productive and underscores that the factors controlling the successive formation of $\mathrm{C}-\mathrm{C}$ bonds under the conditions of the Scholl reaction are still not well understood. ${ }^{17}$

In conclusion, tetrabenzocircumpyrene $\mathbf{1 a}$, a new discshaped nanographene cutout containing 54 carbon atoms, has been efficiently prepared in a simple and practical manner (6 steps from commercially available starting materials), and fully characterized by means of STM. The potential of the route to obtain other related nanographene fragments has also 


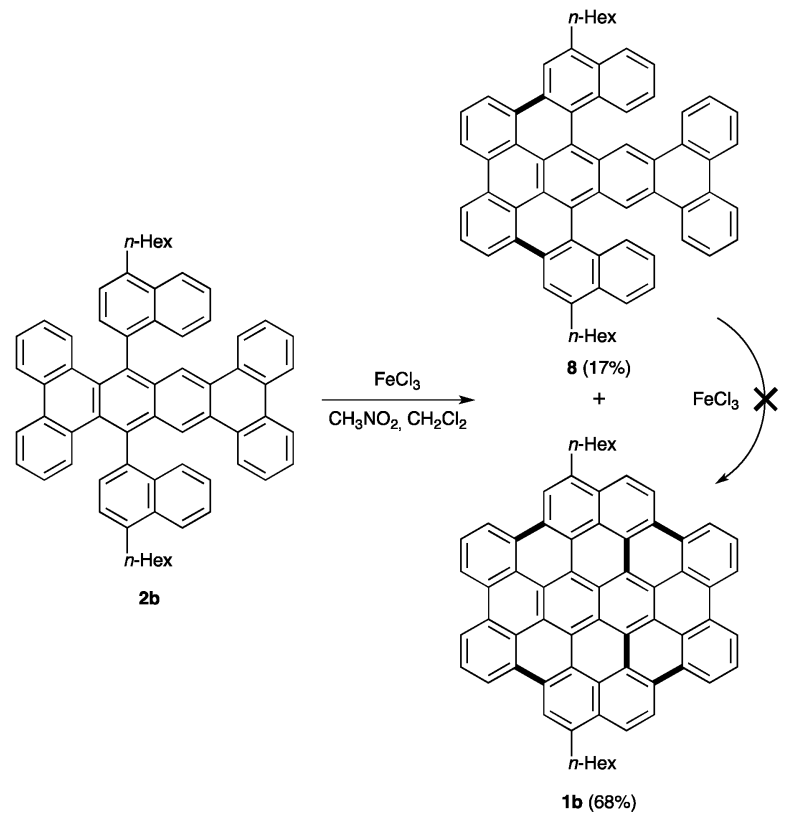

Scheme 4 Scholl cyclodehydrogenation of $\mathbf{2} \mathbf{b}$.

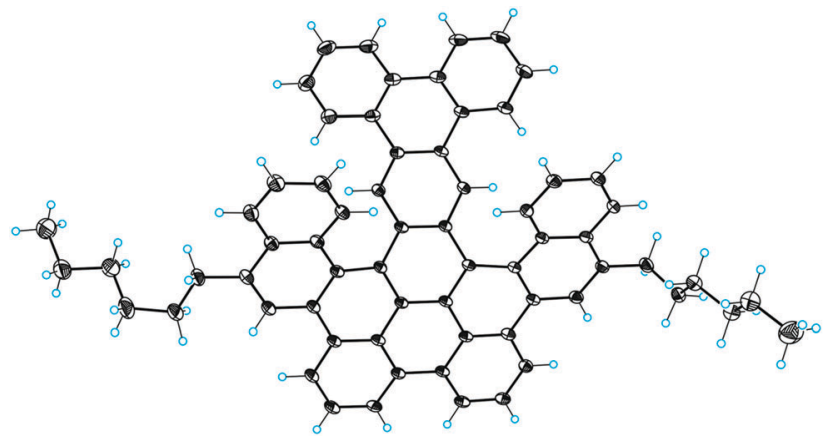

Fig. 5 ORTEP plot (50\% thermal ellipsoids) of the crystal structure of 8 .

been demonstrated. Application of this strategy for the synthesis of larger analogues and other polyrenes with contorted aromatic surfaces is underway.

We thank ATMOL (Contract No. FP7-270028), the European Research Council (Advanced Grant No. 321066), the MINECO (Severo Ochoa Excellence Accreditation 2014-2018 (SEV-2013-0319) and project CTQ2013-42106-P), the AGAUR (2014 SGR 818), and the ICIQ Foundation. We gratefully acknowledge the ICIQ X-ray diffraction, NMR, and Mass Spectrometry units, and SGIker of UPV/EHU for technical support.

\section{Notes and references}

1 (a) J. Wu, W. Pisula and K. Müllen, Chem. Rev., 2007, 107, 718-747; (b) M. D. Watson, A. Fhtecenkötter and K. Müllen, Chem. Rev., 2001, 101, 1267-1300; (c) H. Seyler, B. Purushothaman, D. J. Jones, A. B. Holmes and W. W. H. Wong, Pure Appl. Chem., 2012, 84, 1047-1067; (d) X. Feng, W. Pisula and K. Müllen, Pure Appl. Chem., 2009, 81, 2203-2224; (e) K. Kawasumi, Q. Zhang, Y. Segawa and L. T. Scott, Nat. Chem., 2013, 5, 739-744; $(f)$ L. Chen, Y. Hernandez,
X. Feng and K. Müllen, Angew. Chem., Int. Ed., 2012, 51, 7640-7654; (g) W. Jin, T. Fukushima, A. Kosaka, M. Niki, N. Ishii and T. Aida, J. Am. Chem. Soc., 2005, 127, 8284-8285; (h) K. Müllen and J. P. Rabe, Acc. Chem. Res., 2008, 41, 511-520; (i) S. Fujii and T. Enoki, Acc. Chem. Res., 2013, 46, 2202-2210; (j) K. Müllen, ACS Nano, 2014, 8, 6531-6541.

2 (a) L. T. Scott, Angew. Chem., Int. Ed., 2004, 43, 4994-5007; (b) K. Tahara and Y. Tobe, Chem. Rev., 2006, 106, 5274-5290; (c) B. Schuler, S. Collazos, L. Gross, G. Meyer, D. Pérez, E. Guitián and D. Peña, Angew. Chem., Int. Ed., 2014, 53, 9004-9006; (d) S. J. Hein, H. Arslan, I. Keresztes and W. R. Dichtel, Org. Lett., 2014, 16, 4416-4419; (e) S. Xiao, S. J. Kang, Y. Wu, S. Ahn, J. B. Kim, Y. L. Loo, T. Siegrist, M. L. Steigerwald, H. Li and C. Nuckolls, Chem. Sci., 2013, 4, 2018-2023; $(f)$ Q. Zhang, H. Peng, G. Zhang, Q. Lu, J. Chang, Y. Dong, X. Shi and J. Wei, J. Am. Chem. Soc., 2014, 136, 5057-5064.

3 (a) W. Pisula, X. Feng and K. Müllen, Adv. Mater., 2010, 22, 3634-3649; (b) S. Sergeyev, W. Pisula and Y. H. Geerts, Chem. Soc. Rev., 2007, 36, 1902-1929; (c) W. Pisula, X. Feng and K. Müllen, Chem. Meter., 2011, 23, 554-567; (d) M. Kivala, W. Pisula, S. Wang, A. Mavrinskiy, J.-P. Gisselbrecht, X. Feng and K. Müllen, Chem. - Eur. J., 2013, 19, 8117-8128; (e) L. Chen, X. Dou, W. Pisula, X. Yang, D. Wu, G. Floudas, X. Feng and K. Müllen, Chem. Commun., 2012, 48, 702-704; $(f)$ W. Jin, Y. Yamamoto, T. Fukushima, N. Ishii, J. Kim, K. Kato, M. Takata and T. Aida, J. Am. Chem. Soc., 2008, 130, 9434-9440; $(g)$ F. Hinkel, D. Cho, W. Pisula, M. Baumgarten and K. Müllen, Chem. - Eur. J., 2015, 21, 86-90.

4 Lead references on the synthesis of substituted hexabenzocoronenes: (a) R. Rathore and C. L. Burns, J. Org. Chem., 2003, 68, 4071-4074; (b) X. Feng, J. Wu, V. Enkelmann and K. Müllen, Org. Lett., 2006, 8, 1145-1148; (c) X. Dou, X. Yang, G. J. Bodwell, M. Wagner, V. Enkelmann and K. Müllen, Org. Lett., 2007, 9, 2485-2488; (d) S. H. Wadumethrige and R. Rathore, Org. Lett., 2008, 10, 5139-5142.

5 C. Feng, C. S. Lin, W. Fan, R. Q. Zhang and M. A. Van Hove, J. Chem. Phys., 2009, 131, 194702.

6 Q. Ye and C. Chi, Chem. Mater., 2014, 26, 4046-4056.

7 (a) A. Konishi, Y. Hirao, M. Nakano, A. Shimizu, E. Botek, B. Champagne, D. Shiomi, K. Sato, T. Takui, K. Matsumoto, H. Kurata and T. Kubo, J. Am. Chem. Soc., 2010, 132, 11021-11023; (b) A. Konishi, Y. Hirao, K. Matsumoto, H. Kurata, R. Kishi, Y. Shigeta, M. Nakano, K. Tokunaga, K. Kamada and T. Kubo, J. Am. Chem. Soc., 2013, 135, 1430-1437; (c) L. Zöphel, R. Berger, P. Gao, V. Enkelmann, M. Baumgarten, M. Wagner and K. Müllen, Chem. - Eur. J., 2013, 19, 17821-17826; (d) A. Sun, Z. Zeng and J. Wu, Acc. Chem. Res., 2014, 47, 2582-2591.

8 A. Narita, X. Feng, Y. Hernandez, S. A. Jensen, M. Bonn, H. Yang, I. A. Verzhbitskiy, C. Casiraghi, M. R. Hansen, A. H. R. Koch, G. Fytas, O. Ivasenko, B. Li, K. S. Mali, T. Balandina, S. Mahesh, S. De Feyter and K. Müllen, Nat. Chem., 2013, 6, 126-132.

9 (a) L. B. Roberson, J. Kowalik, L. M. Tolbert, C. Kloc, R. Zeis, X. L. Chi, R. Fleming and C. Wilkins, J. Am. Chem. Soc., 2005, 127, 3069-3075; (b) B. H. Northrop, J. E. Norton and K. N. Houk, J. Am. Chem. Soc., 2007, 129, 6536-6546.

10 (a) J. Aihara, J. Phys. Chem. A, 1999, 103, 7487-7495; (b) Y. Ruiz-Morales, J. Phys. Chem. A, 2002, 106, 11283-11308; (c) D. Moran, F. Stahl, H. F. Bettinger, H. F. Schaefer III and P. V. R. Schleyer, J. Am. Chem. Soc., 2003, 125, 6746-6752; (d) X. L. Fan, X. Q. Wang, J. T. Wang and H. D. Li, Phys. Lett. A, 2014, 378, 1379-1382.

11 (a) N. Tyutyulkov, G. Madjarova, F. Dietz and K. Müllen, J. Phys. Chem. B, 1998, 102, 10183-10189; (b) F. Dietz, N. Tyutyulkov, G. Madjarova and K. Müllen, J. Phys. Chem. B, 2000, 104, 1746-1761.

12 L. H. Klemm, E. Hall, L. Cousins and C. E. Klopfenstein, J. Heterocycl. Chem., 1987, 24, 1749-1755.

13 M. Juaristi, J. M. Aizpurua, B. Lecea and C. Palomo, Can. J. Chem., 1984, 62, 2941-2944.

14 M. P. Cava and D. R. Napier, J. Am. Chem. Soc., 1957, 79, 1701-1705.

15 CCDC 1035605 (4), 1035606 (2a), 1035608 (2b), 1035607 (2c), 1035609 (2d) and 1035610 (8).

16 H. Arslan, F. J. Uribe-Romo, B. J. Smith and W. R. Dichtel, Chem. Sci., 2013, 4, 3973-3978.

17 D. Lorbach, M. Wagner, M. Baumgarten and K. Müllen, Chem. Commun., 2013, 49, 10578-10580. 